\title{
Development of generalized tool life model for constant and variable speed turning
}

\author{
Paolo Albertelli ${ }^{1,2}$ (D) Valerio Mussi ${ }^{2} \cdot$ Michele Monno $^{1,2}$ \\ Received: 1 May 2021 / Accepted: 6 September 2021 / Published online: 23 September 2021 \\ (C) The Author(s) 2021
}

\begin{abstract}
In this research, a generalized tool life modelling for considering non-stationary cutting conditions was developed . In particular, for the first time in literature, the model was conceived for predicting the life of the tool when spindle speed variation $S S V$, one of the most effective techniques for suppressing regenerative chatter vibrations, is used. The proposed formulation takes into account the main cutting parameters and the parameters associated to the $S S V$. A dedicated experimental campaign of turning tests was executed and the data were used for modelling purposes. The model validation was carried out performing additional tool life tests. According to the analyzed technological scenario, it was found that the generalized formulation can be used for predicting the tool life both at constant spindle machining CSM and adopting SSV with the maximum estimating error of $6 \%$.
\end{abstract}

Keywords Tool life modeling $\cdot$ Spindle speed variation $\cdot$ Non-stationary cutting $\cdot$ Chatter suppression

\section{Introduction}

The occurrence of high vibrations in machining limits the achievable Material Removal Rate $M R R$ [1], the surface quality and the tool life $T L$ [2]. Vibrations are typically due to regenerative effects that bring cutting process to instability. Spindle speed variation $(S S V)$ is one of the available techniques for suppressing chatter vibrations [3]. It is based on a continuous modulation of the spindle speed that aims at repressing the regenerative effect and thus the growth of undesired vibrations. Over the years, $S S V$ has been developed and tested both in turning and milling applications. First, studies assessed the vibration mitigation properties of the spindle speed variation $S S V$. Radulescu

Paolo Albertelli

paolo.albertelli@polimi.it

Valerio Mussi

valerio.mussi@musp.net

Michele Monno

michele.monno@polimi.it

1 Mechanical Engineering Department, Politecnico di Milano, via La Masa 1, 20156 Milan, Italy

2 Consorzio MUSP, strada Torre della Razza, 29122 Piacenza, Italy et al. [4] developed a time domain model for this purpose. Insperger et al. [5, 6] developed an analytical formulation for predicting the stability map when the $S S V$ is adopted. The model was validated through simulations. The same approach was used by Kapoor et al. [7]. Albertelli et al. [8] developed a time domain simulation model for studying $S S V$ in turning. The model was validated through experimental tests. Urbikain et al. [9] studied the effect of $S S V$ on the stability map in a real turning application through the perturbation theory. Yamato et al. [10] studied the stability of variable delay turning through an energy approach. Zhang and Ni [11], adopting a similar method, provided useful indications for selecting the $S S V$ parameters. The approach was tested through numerical simulations. Otto and Radons [12] studied the effectiveness of $S S V$ in turning according to different eigenfrequencies and damping ratios. Wu and Chen [13] extended the application of $S S V$ to non-circular turning. Ding et al. [14] developed a control strategy based on the simultaneous adjusting of the parameters governing the $S S V$. They demonstrated the validity of the proposed approach through simulations and executing some preliminary cutting tests. The same authors in [15] developed a close-loop implementation that combined monitor and control strategies suitable for turning applications. Meng et al. [16] developed a state feedback control for assuring the steady state stability in $S S V$ turning. They tested the control strategy through 
simulations. Zatarain et al. [17] carried out milling simulations and experimentally validated the numerical findings. Totis et al. [18] developed an analytical formulation for fast estimating the stability maps when the $S S V$ is adopted in milling. A proper experimental validation was not provided. Sinusoidal spindle speed variation $S S S V$ is the most studied approach for modulating the spindle speed. Alternative approaches were developed. For instance, Yilmaz et al. [19] conceived an approach based on a pseudo-random spindle speed variation. Nam et al. [20] recently developed a $S S V$ strategy characterized by a constant acceleration rate that allowed achieving higher $M R R$ than conventional $S S V$. The same authors in [21] defined novel chatter indices for assessing the chatter growth. Albertelli et al. [22] developed a generalized algorithm based on cyclostationary theory for chatter detection when the spindle speed variation is used.

From the quantitative perspective, it was proven that stability enhancement due to $S S V$ is effective and robust especially in the high-order lobes region of the stability maps, both in turning [8] and milling [17]. The $S S V$, thanks to the the stabilization capabilities, reduces the risk of tool chipping and too early failures that typically occur when vibrations affect the cutting [23]. Although several research works have been published on $S S V$ so far, few of them focused on potential secondary detrimental effects of the technique. For instance, Albertelli [8] studied the thermal load of the spindle motor due to the spindle modulation and performed a feasibility study with respect to industrial turning applications. Urbikain et al. [9] found that $S S V$ slightly increased (about 20\%) the power consumption of the lathe. For what concerns the tool duration, Albertelli et al. [24] found that sinusoidal spindle speed variation $S S S V$ has a negative impact on the life of the tool, fostering the formation of cracks that tend to progressively detach the coating and thus increasing the wear rate. In this study, the achieved results were obtained comparing $S S S V$ machining to constant speed machining CSM, both in stable conditions. Chiappini et al. in [25] used a finite element model $F E M$ for simulating $S S S V$ cutting. It was found that the modulation of the spindle speed is the responsible of an additional mechanical-thermal load on the cutting edge that could bring to the cracks formation. Although both the research works gave an interesting interpretation of the involved phenomena, a quantification of the tool life $T L$ reduction, according to the adopted cutting parameters, was not provided. Being able to quantify the $T L$ reduction would be extremely useful for assessing the potentialities and the limitations of the $S S S V$, especially in terms of industrial applicability. Although variable speed machining VSM was first conceived in the 1970s, its wide diffusion in real applications has not been registered so far. For instance, the use of such technique to stabilize machining operations that otherwise could be regularly carried out with stiffer, but even more expensive machines, needs to be properly analyzed. In such way, a trade off between tooling and machine costs could be investigated. In order to bridge this gap, in this paper a generalization of the Taylor's model for estimating the $T L$ in turning, when both $C S M$ and $S S S V$ are indiscriminately used, was developed.

The literature on the study of the wear of the tool is huge. Some of the works focused on the performance assessment of new tool materials and coatings. For instance, Wojciechowski et al. [26] assessed the performance of Boron Nitride Dispersed Cemented Carbide on a specific spheroidal cast iron focusing on the main wear phenomena. Wojciechowski and Twardowski [27] compared the duration of sintered carbide and cubic boron nitride in hardened steel milling without developing a proper tool life modelling. Even the effects of the adopted cooling lubrication strategy on the tribological behaviour [28] and on energy consumption have been subject of several studies [29]. Cryogenic cutting allows reducing the specific energy involved in cutting. Comparative studies on the life of the tool were carried out. For instance, Albertelli et al. [30] developed a tool life modelling considering conventional and cryogenic Ti6Al4V milling. Cryogenic cutting showed increments in tool duration only if high cutting speeds were adopted. Although Wong et al. [31] put into evidence the limitation of the empirical approaches, Johansson et al. [32], performing an interesting assessment of different tool life modelling formulations, found that Taylor's model assured a tool life estimation error that ranged from $8 \%$ to $21 \%$ and that the error was not material dependant.

So far, the literature that has been dealt with the tool wear under unstationary cutting conditions is rather poor. For instance, Galante et al. [33] developed a new tool life modelling approach based on Gaussian probability distribution that allows developing more flexible models with respect to the Taylor's model. One of the first studies that presented the difficulties related to the wear modelling when different cutting conditions are set was carried out by Jemielniak et al. in [34]. Lin in [35] and Pálmai in [36] proposed a cumulative wear model for taking into considerations different spindle speed steps. Since, to the authors' knowledge, no specific modelling approaches for estimating the $T L$ when the cutting speed is continuously modulated have been developed, a preliminary formulation is first presented in this study. The paper was structured as follows. In Section 2, a more exhaustive description of the research goals together with the explanation of the conceived approach were provided. The experimental set-up, the designed experimental campaign and the preliminary tests were also presented. In Section 3, the results of the experimental tests, the development of the modelling formulations and their validation were reported 
and critically analysed. In Section 4, the conclusions were also outlined.

\section{Nomenclature}

$\boldsymbol{\beta}$ regression coefficients

$\hat{\boldsymbol{\beta}}$ regression coefficient estimations

$\boldsymbol{L}$ least square function

$\boldsymbol{X}$ regression variables matrix

$\boldsymbol{y}$ response variables vector

$\chi$ primary tool lead angle

$\Delta A_{\Omega} \%$ percentage tracking error with respect to the set $A_{\Omega \text { set }}$

$\triangle R V A \%$ percentage tracking error with respect to the set $R V A_{\text {set }}$

$\hat{T L_{S}} \quad T L$ estimation carried out with the $s$ th formulation

$\Omega \quad$ Spindle speed

$\Omega_{0} \quad$ Nominal spindle speed

$\Omega_{0 \text { set }}$ nominal imposed spindle speed

$\Omega_{\text {meas }}(t)$ measured spindle speed through the spindle encoder

$\Omega_{\text {set }}(t)$ imposed spindle speed set-point

$a_{p}$ radial depth of cut

$A_{\Omega} \quad$ amplitude of the sinusoidal modulation of the spindle speed

$A_{B_{i k}} \quad$ area of the wear land on the tool flank

$C I$ confidence interval

$C T_{i(p+1)}$ cutting time associated to the average flank width $V B B_{i(p+1)}$

$C T_{i p}$ cutting time associated to the average flank width $V B B_{i p}$

$D F_{j} \quad$ degrees of freedom of the factor $j$

$f$ feed per revolution

$F-$ value $_{j} \quad$ Fisher tests for the factor $j$

freq frequency of the sinusoidal spindle variation $S S S V$

$H_{0 j} \quad$ null hypothesis for the $j^{\text {th }}$ paired $C S M-S S S V$ test

$l_{B_{i k}}$ length of the wear area used for the $V B B_{i k}$ computation

$m$ number of considered factors in the $2^{m}$ experimental plans

$M S_{j} \quad$ Mean Squares of the factor $j$

$n_{r c} \quad$ number of replicates of the central points

$n_{r} \quad$ number of replicates of tests carried out at the corner points

$P$ - value $j \quad P$ value of the test for the factor $j$

$R^{2} \quad$ coefficient of determination of the regression

$R_{a d j}^{2}$ adjusted coefficient of determination of the regres-

$r_{\epsilon} \quad$ insert corner radius

$R V A$ non-dimensional amplitude variation of the sinusoidal spindle variation $S S S V$ : sinusoidal amplitude/ $\Omega_{0}$

$S E \quad$ standard error
$S S_{j}^{I I I} \equiv S S_{(j \mid k, \ldots, r)} \quad$ adjusted sum of squares (type $\left.I I I\right)$ of the factor $j$

$S S_{(j, k, \ldots, r)}$ sequential sum of square (type I) considering the factors $j, k, \ldots, r$ in the model

$t$ time

$T L$ tool life

$T L_{i} \quad$ Tool Life $T L$ of the $i$ th tested cutting edge

$T L_{s-e r r o r \%}$ percentage errors in the $T L$ estimation adopting the $s$ th formulation

$v_{c} \quad$ cutting speed

$V B B \quad$ flank wear average width

$V B B_{t} \quad$ flank wear width threshold

$V B B_{i k_{j}} \quad$ local measurement of the flank width $V B B$ after the $k$ th stop of the $i$ th wear test

$V B B_{i k}$ is the $k$ th measurement of the average flank width associated to the $i$ th wear test

$X_{n}$ radial coordinate-distance from the external surface (micro-hardness measurements)

\section{Material and methods}

According to [8], even in this research experimental tool wear tests (ISO 3685, [37]) were performed both in constant speed $C S M$ and variable speed $V S M$ machining. The definition of the tests was carried out adopting a Design of Experiments $D O E$ approach. More specifically, in both the cases a full factorial scheme was used and properly motivated. Additional information were provided in Section 2.1. The tool life $T L$ data were analyzed and used for the generalized regression model development. A proper validation was even carried out.

\subsection{Design of experiments}

A steel turning application was selected. Indeed, for the cutting speeds typically adopted in steel machining and considering the limiting eigenmodes generally associated to tool-holder systems $(70-160 \mathrm{~Hz})$, it was demonstrated that $S S S V$ can assure effective chatter suppression properties [8]. Moreover, such application is rather widespread in most of the shop-floors.

In this research, two levels full factorial designs $2^{m}$ ( $m$ is the number of the considered factors) were conceived for the tests performed at CSM and for the tests that involved the sinusoidal spindle speed modulation SSSV . Although other design of experiments schemes allow to reduce the experimental effort (i.e. Taguchi, Box-Behnken), it was decided to use a full factorial scheme since it provides a more flexible approach especially if it is necessary to combine and analyze the results of the two separate experimental sessions. Moreover, Tsui [38] found that Taguchi approach 
can lead to non-optimal solutions, information loss and efficiency loss. Indeed, Medan et al. [39] obtained better estimation errors adopting a full factorial design instead of using Taguchi. Box-Behnken is a factorial scheme with an incomplete block design that can lead to regions of poor prediction quality (corners), Montgomery [40].

For both the experimental plans, the cutting velocity $v_{c}$ and the feed per revolution $f$ were the main analyzed factors. Since the $S S S V$ can be described by Eq. 1, two additional factors were considered: $R V A$ and freq. $R V A$ is the non-dimensional amplitude variation parameter while freq is the frequency parameter. It is worth noting that, since the spindle modulation makes the chip thickness to continuously vary $[8,25]$, the $f$ parameter was considered in the experimentation at $C S M$ although, according to the Taylor's theory, the effect of such parameter should be less relevant than $v_{c}$.

$$
\begin{aligned}
\Omega(t) & =\Omega_{0}(1+R V A \cdot \sin (2 \pi \cdot \text { freq } \cdot t)) ; \\
A_{\Omega} & =R V A \cdot \Omega_{0}
\end{aligned}
$$

For what concerns the radial depth of cut $a_{p}$, since it is well-known in literature (i.e. Johansson et al. [32] and Hägglund [41]) that its effect on the wear of the tool is less relevant than $f$ and considering the need to limit the experimental resources, this parameter was not varied in the experimentation. For this purpose, a radial depth of cut $a_{p}=2 \mathrm{~mm}$ was set. This choice simultaneously took into consideration some aspects:

- high $a_{p}$ values should be used since $S S V$ is typically used for rough machining

- high $a_{p}$ values should be used in order to avoid the effect of the radius of the tool in the flank wear measurement (see Fig. 5).

- $a_{p}$ should be lower than the active part of the cutting edge $(6 \mathrm{~mm})$

- should be limited in order to consider the lathe limitations in terms of maximum spindle torque and power.

- $a_{p}$ should be limited to avoid chatter vibrations [1]. Preliminary cutting tests were performed in order verify the absence of any dangerous vibrations (see Section 2.3).

For all the analyzed factors $\left(v_{c}, f, R V A\right.$, freq) two levels were considered. Moreover, in order to track possible deviations from the linearity (i.e. curvatures due to second order effects with respect to the considered factors) or to enhance the model adequacy as well, center points were added to the $2^{m}$ factorial design scheme. In case of curvature effects (assessment performed in Section 3.1 and Section 3.2), additional test conditions can be added. To restrict the experimental effort/budget, it was decided to carry out one single test $n_{r}=1$ for each corner condition [40] while $n_{r c}=5$ replicates were set for the intermediate cutting conditions, left side of Fig. 10. Finally, it was decided to use the described approach for the following reasons:

- Since it was found $[24,42]$ that the wear mechanisms in variable speed machining $V S M$ are rather common in tool wear tests, the expected deviations from the Taylor's model (linear with respect to the factors in logarithmic coordinates) were supposed to be limited

- The Analysis of Variance (ANOVA) theoretical framework (Montgomery [40]) provides suitable tools for statistically assessing the curvature effects

- The adequacy of the proposed approach can be further verified selecting, for the model validation phase, different cutting conditions from the ones used for the modelling step (Section 3.4).

The analyzed factors and the corresponding selected values, both for CSM and SSSV, were resumed in Tables 1 and 2 , respectively. The values of the analyzed factors were chosen according to [42] and considering the technological limitations associated to the adopted tool $\left(v_{c}\right.$ and $f$ ) and lathe. Indeed, the set parameters allow continuously changing the cutting speed in the SSSV tests. Preliminary turning tests were carried out in order to check the feasibility of both the $D O E$ plans (Section 2.3). Moreover, it was demonstrated in [8] that the selected parameters ( $R V A$ and $f$ req) assured relevant chatter suppression properties if unstable cut occurred. It is worth noting that all the tests in this experimental campaign were executed in stable conditions (Section 2.3). All the cutting tests (both at CSM and adopting $S S S V$ ) were completely randomized. More details on the experimental set-up were reported in Section 2.2.

\subsection{Experimental set-up}

The flank wear average width $V B B$ was monitored during the cutting tests. The flank wear threshold $V B B_{t}=$ $0.15 \mathrm{~mm}$ was used as the end-of-tool-life criteria. The cutting time $T L$ that corresponds to the considered wear threshold was the main process response for all the tested conditions. Although the selected wear threshold $V B B_{t}=$ $0.15 \mathrm{~mm}$ is lower than the ones typically used and suggested by the ISO 3685 [37], preliminary wear tests confirmed that the chosen threshold avoided a too high dispersion of the results in terms of insert duration $T L$. This choice was carried out to limit the experimental effort. Steel bars

Table 1 Design of experiments-CSM, factors and values

\begin{tabular}{lll}
\hline Level & $v_{c}(\mathrm{~m} / \mathrm{min})$ & $f(\mathrm{~mm} / \mathrm{rev})$ \\
\hline High & 220 & 0.3 \\
Center & 190 & 0.2 \\
Low & 160 & 0.1 \\
\hline
\end{tabular}


Table 2 Design of experiments- $S S S V$, factors and values

\begin{tabular}{lllll}
\hline Level & $v_{c}(\mathrm{~m} / \mathrm{min})$ & $f(\mathrm{~mm} / \mathrm{rev})$ & $R V A$ & freq $(\mathrm{Hz})$ \\
\hline High & 220 & 0.3 & 0.3 & 1.5 \\
Center & 190 & 0.2 & 0.2 & 1 \\
Low & 160 & 0.1 & 0.1 & 0.5 \\
\hline
\end{tabular}

(material 39NiCrMo3, with hardness $255 \mathrm{HB}$, ultimate tensile strength $1145 \mathrm{MPa}$, Yield strength $1015 \mathrm{MPa}$ and an elongation at break $14.5 \%$ (UNI $7845-78$ [43])) hardened and tempered were used to perform the wear tests. The tool life tests were performed following the standard ISO3685 [37]. A Stereomicroscope Optika SZN - T with a Motic SMZ - $168 T$ was used to measure flank wear width $V B B$ during the cutting tests. More details on the performed wear measurements can be found in Albertelli et al. [42]. A carbide tool with a lead angle $\chi=95^{\circ}$ was adopted (ISO code TNMG220404 M5 5625 (tool radius equal to $r_{\epsilon}=0.4 \mathrm{~mm}$, rake angle $13^{\circ}$ and a relief angle equal to $0^{\circ}$ with a $A l 2 O 3-$ TiCN coating)) and fixed on tool holder, ISO code MT JNL2525M22. Cutting fluid (oil-water emulsion with $5 \%$ of HOCUT $795 S C$ ) was used in order to reproduce realistic industrial machining conditions. The lubricant was injected to the cutting zone through a flexible and adjustable nozzle, visible also in Fig. 1. It is worth noting that a proper control unit was specifically developed (adopting National Instruments NI hardware and software) for performing the cutting tests in VSM. Specifically in this research, a $\Omega_{0 s e t}-R V A_{\text {set }}-$ freq $_{\text {set }}$ parameter combination can be set to the controller to perform cutting tests with the $S S S V$. The conceived solution was integrated with the drives and the numerical controller a SOMAB Unimab 400 lathe, refer to Fig. 1. Since it was not possible to use $N C$ build-in functions for modulating the spindle speed, a tailored solution was developed. A circuit allowed to change the operating mode $C S M / S S S V$. If the SSSV mode was selected, the spindle speed setpoint $\Omega_{\text {set }}(t)$ was generated by the external control system. If the CSM mode was selected, the speed set-point was directly generated by the numerical controller $N C$ of the lathe. In both the cases the speed set-point $\Omega_{\text {set }}(t)$ and the measured spindle speed $\Omega_{\text {meas }}(t)$ (through the spindle encoder) were acquired. The lathe was equipped with a spindle with a maximum power of $12.5 \mathrm{~kW}$ that can rotate up to $3000 \mathrm{rpm}$. A preliminary version of such control unit described in Albertelli et al. [42]. A Kistler dynamometer $(9265 B)$ with the associated charge amplifier $(5070 A)$ was used to measure the cutting force during the preliminary phases of the experimentation (see Section 2.3).

\subsection{Preliminary verifications}

Before executing the wear tests, some preliminary checks were carried out:

- lathe tracking performance verification

- workpiece hardness analysis

- verification of chatter free cutting conditions

- dispersion of the tool life data according to the selected wear threshold $V B B_{t}=0.15 \mathrm{~mm}$

The first verification was performed in order to exclude any side effects of the tracking performance of the developed
Fig. 1 Experimental set-up: lathe and developed control unit

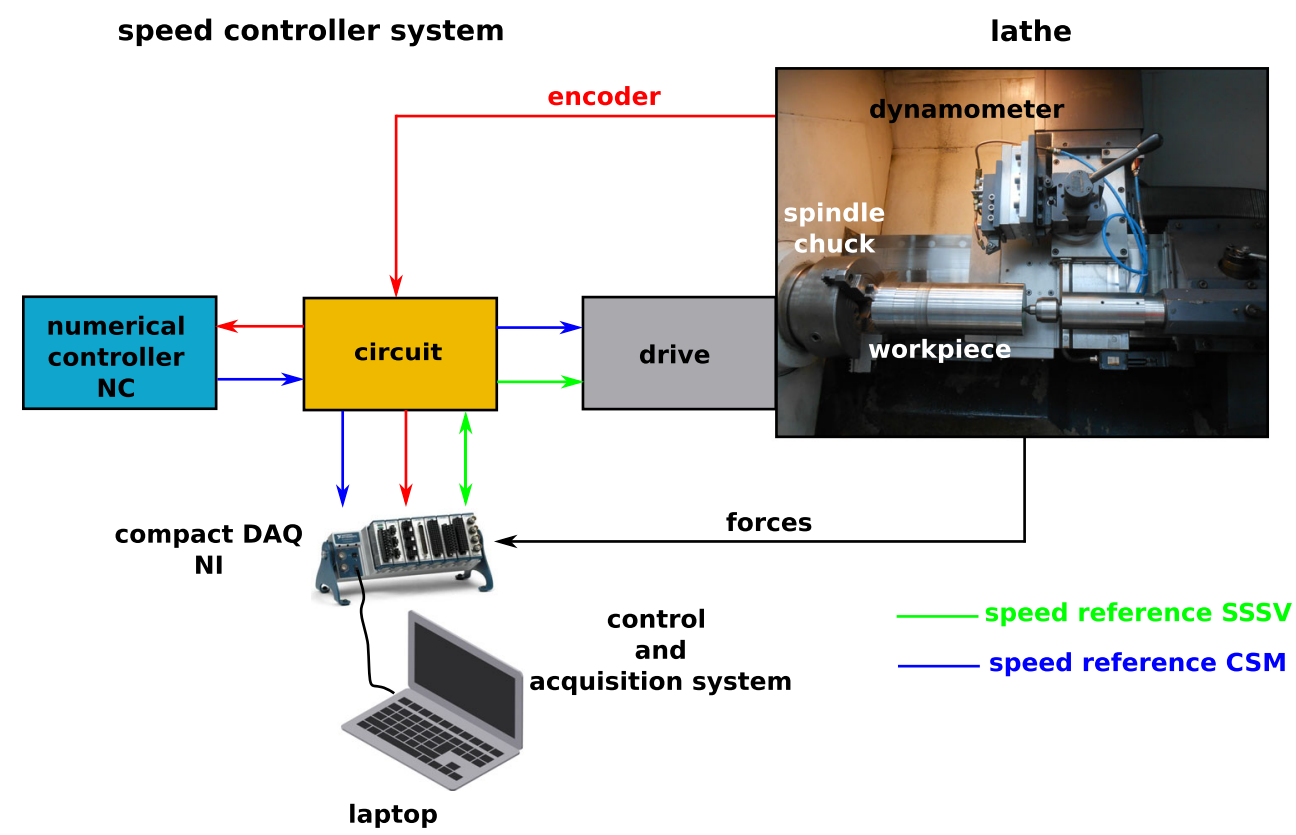


control unit, especially when the SSSV was adopted, on the results of the experimentation. More specifically, since the spindle available torque is limited, the SSSV cannot be arbitrary implemented. Moreover, the maximum achievable speed modulation (in terms of combination of $R V A$ and freq) depends on the nominal cutting speed. Several spindle speed tracking tests were carried out to assess the limitations of the adopted equipment (Fig. 1). All the tracking tests in the $S S S V$ regime were executed with workpiece hold by the spindle in order to reproduce as much as possible the real cutting conditions (workpiece inertia). For each selected combination of $S S S V$ parameters $\left(R V A_{\text {set }}\right.$ and freq $\left._{\text {set }}\right)$, the imposed spindle speed $\Omega_{0 \text { set }}$ was progressively increased. During each run, the actual spindle speed $\Omega_{\text {meas }}(t)$ was acquired through the spindle encoder (see Fig. 1) and the developed acquisition system. A Fast Fourier Transform FFT was carried out in order to estimate the average spindle speed $\bar{\Omega}_{0 \text { meas }}$, the resulted modulation $A_{\Omega}$ meas and the corresponding $R V A_{\text {meas }}$. In Table 3, some results were reported. The percentage tracking errors $\left(\Delta A_{\Omega} \%\right.$ and $\left.\Delta R V A \%\right)$ in terms of deviation from the nominal values (respectively $A_{\Omega}$ set and $R V A_{\text {set }}$ ) was computed. Even in Fig. 2, it can be observed that up to $1000 \mathrm{rpm}$ the tracking errors are negligible while just starting from $1200 \mathrm{rpm}$ they become unacceptable. Several additional tests were carried out with different combinations of $R V A_{\text {set }}-$ freq $_{\text {set }}$.

The second verifications was carried out for investigating if the workpiece hardness changes according to the machined region. Indeed, a non-homogeneous material property could have affected the reliability of the tool life tests introducing a possible bias. In order to exclude such effect, several hardness measurements were performed. Both macro-hardness and micro-hardness measures were carried out on different workpiece locations as reported in Fig. 3. Macro-hardness measurements were executed on the lateral part of the workpiece $(\varnothing=132 \mathrm{~mm})$ both on the external raw surface (zone $C$ ) and on the internal turned part (zone $B$ of $\varnothing=130 \mathrm{~mm}$ ). The macro-hardness data were statistically analyzed and it was confirmed that the hardness measured in the zone $C$ cannot be be considered different from the one measured in zone $B$. An additional analysis was carried out investigating the dependence of

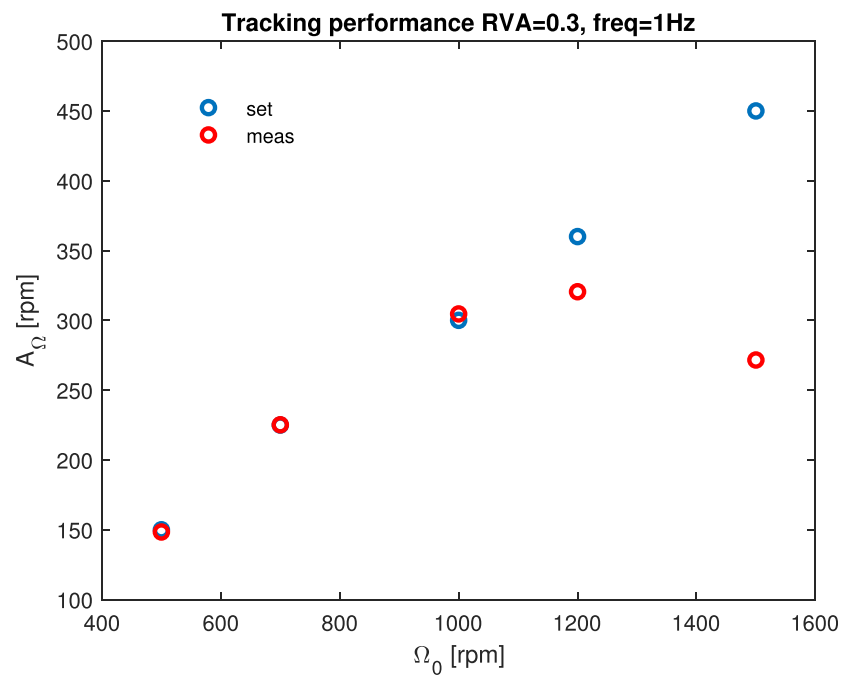

Fig. 2 Tracking errors $R V A=0.3$ freq $=1 \mathrm{~Hz}: A_{\Omega}$ set and $A_{\Omega}$ meas

the hardness on the radial coordinate $X$ : three microhardness repetitions (durometer Future - Tech F M -700, Vickers, loading $1 \mathrm{~kg}$, dwell time $15 \mathrm{~s}$ ) were performed increasing the distance $X_{n}$ from the external surface zone $B$. The micro-hardness measurements were executed on the cross-section zone A, properly prepared through multiple polishing steps. The obtained results were reported in Fig. 4. It was statistically demonstrated that the hardness cannot be considered affected by the radial coordinate $X$.

Both the performed verifications allowed to adequately plan the experimental campaign for the wear tests. Since the experimented tracking limitations and the fact that the bars to be machined can be considered homogeneous it was decide to partially randomize the tool life tests in order to limit the wasted material. Indeed, the cutting tests at high velocity $v_{c}$ were carried out machining the external parts of the bars as far as the tracking limitations occurred and the remaining part of the workpieces were used for the low cutting speed tests.

Before executing the whole experimentation (tool life tests), all the cutting conditions (combining the cutting parameters as reported in Tables 1 and 2) were tested in order to verify the absence of any undesired vibrations (i.e. due to regenerative chatter) that can negatively affect

Table 3 Tracking performance verification - example $(R V A=0.3$, freq $=1 \mathrm{~Hz})$

\begin{tabular}{llllllll}
\hline$\Omega_{0 \text { set }}(\mathrm{rpm})$ & $R V A_{\text {set }}$ & freq set $(\mathrm{Hz})$ & $A_{\Omega \text { set }}(\mathrm{rpm})$ & $A_{\Omega \text { meas }}(\mathrm{rpm})$ & $\Delta A_{\Omega} \%$ & $R V A_{\text {meas }}(\mathrm{rpm})$ & $\Delta R V A \%$ \\
\hline 500 & 0.3 & 1 & 150 & 148.4 & -1.06 & 0.2975 & -0.85 \\
700 & 0.3 & 1 & 225 & 225.2 & +0.08 & 0.3001 & +0.03 \\
1000 & 0.3 & 1 & 300 & 304.6 & +1.53 & 0.3047 & +1.58 \\
1200 & 0.3 & 1 & 360 & 320.5 & -10.97 & 0.2707 & -9.8 \\
1500 & 0.3 & 1 & 450 & 271.6 & -39.65 & 0.1892 & -36.9 \\
\hline
\end{tabular}




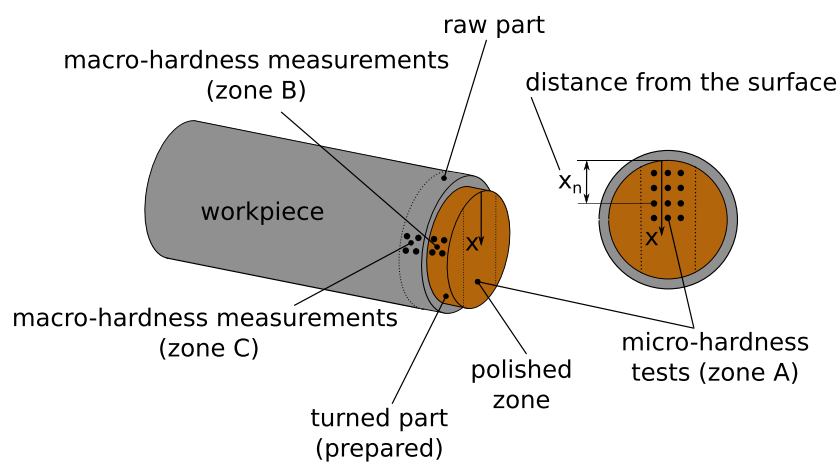

Fig. 3 Workpiece hardness analysis-effects of the position

the life of the tool. For this purpose, the cutting forces were measured with the Kistler dynamometer and analyzed performing a $F F T$. No critical frequency components were found in the computed spectra for $a_{p}=2 \mathrm{~mm}$. The performed tests confirmed that the selected radial depth of cut is far from the stability limit.

As anticipated, preliminary wear tests were executed in order to verify the adequacy of the selected wear threshold $V B B_{t}=0.15 \mathrm{~mm}$. Repeated tests (wear tests carried out adopting the same cutting parameters) revealed that the wear rate is rather high when the flank shows an average wear land width close to $0.15 \mathrm{~mm}$ (see also Figs. 5 and 6). This allowed to proper discriminate the threshold overcoming and, as a consequence, to limit the dispersion of tool life $T L$ data that typically occurs when the wear rate is low. The low dispersion of the tool life data $T L$ can be even appreciated in Fig. 8 that describes the evolution of the flank wear for the repetitions of the tests executed with the center point conditions.

\subsection{Tool wear analysis}

For the $i$ th tested insert, a set of $n V B B$ measurements is available $\overline{V B B}_{i}=\left\{V B B_{i 1}, V B B_{i 2}, \cdots, V B B_{i k}, \cdots\right.$,

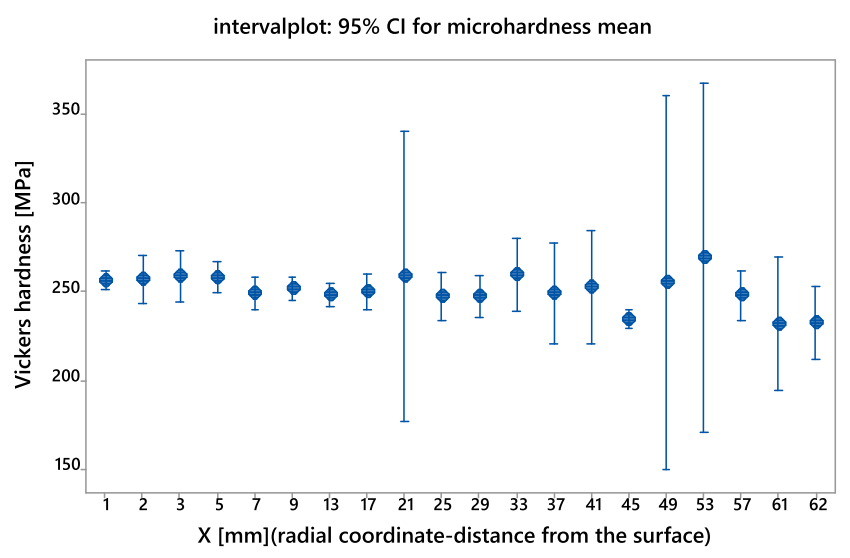

Fig. 4 Micro-hardness measurements

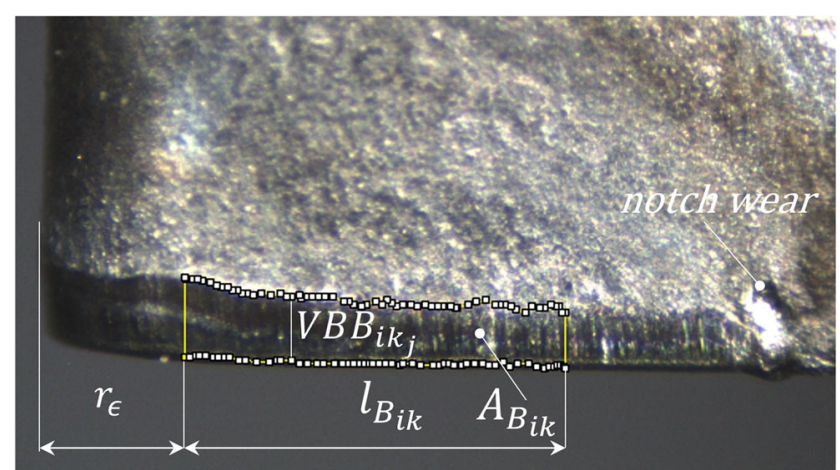

Fig. 5 Flank wear land analysis: average flank width computation $V B B_{i k}$

$\left.V B B_{i p}, V B B_{i(p+1)}, \cdots, V B B_{i n}\right\}$ where $V B B_{i k}$ is the generic $k$ th measurement of the average flank width (performed after the $k$ th stop). According to ISO 3685 [37], the $V B B_{i k}$ was computed using Eq. 2 where $V B B_{i k_{j}}$ is the local measurement of the flank width (see Fig. 5). Integrating the $V B B_{i k_{j}}$ over the length $l_{B_{i k}}$ of the analyzed region, the area $A_{B_{i k}}$ of the wear land and the $V B B_{i k}$ can be computed. The flank width measurements $V B B_{i k_{j}}$ were performed, as suggested by ISO 3685 [37], on the rectilinear portion of the insert avoiding the curvilinear part (length $r_{\epsilon}$ ) and the portion of the wear land affected by the notch (see Fig. 5). The $T L_{i}$ can be estimated linearly interpolating two subsequent cutting times $\left(C T_{i p}\right.$ and $\left.C T_{i(p+1)}\right)$ that were associated respectively at the $p$ th and the $(p+1)$ th stops. Moreover, $V B B_{i p}$ and $V B B_{i(p+1)}$ fulfill the relationship reported in Eq. 4. It was verified that the linear assumption between the wear and the tool life assured a proper accuracy since several $V B B$ measurements for each wear test were available and the $V B B_{i(p+1)}$ and

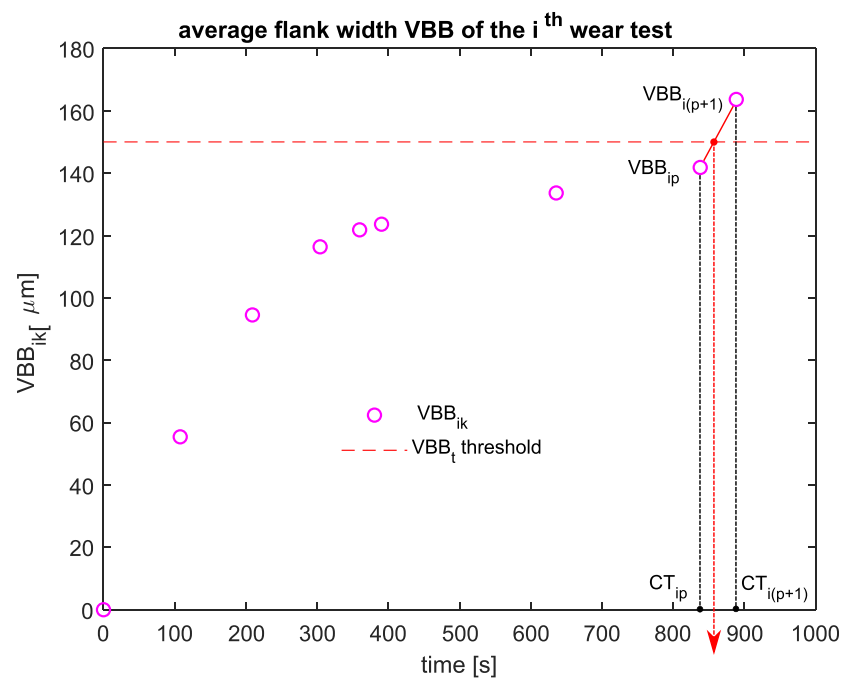

Fig. 6 Example of the evolution of the average flank wear evolution $V B B_{i k}$ of the $i$ th test 
$V B B_{i p}$ are rather closed. It was found that a higher order polynomial fitting of the $V B B(T L)$ curve brought to deviations in the estimated tool life $T L_{i}$ less than $1 \%$.

$V B B_{i k}=A_{B_{i k}} / l_{B_{i k}}=1 / l_{B_{i k}} \cdot \int_{0}^{l_{B_{i k}}} V B B_{i k_{j}} d l$

$T L_{i}=C T_{i p}+\frac{C T_{i(p+1)}-C T_{i p}}{V B B_{i(p+1)}-V B B_{i p}} \cdot\left(V B B_{t}-V B B_{i p}\right)$

$V B B_{i p}<V B B_{t}<V B B_{i(p+1)}$

\subsection{Tool life modelling and validation}

All the acquired data were statistically analyzed through the Analysis of Variance ANOVA. For what concerns the modelling approach, a multiple linear regression was adopted [40]. In the present research, the $T L$ data or a transformation of them, were considered in the response variables vector $\boldsymbol{y}=\left[y_{1}, y_{2}, \cdots, y_{n}\right]$ while the main analyzed factors, a sub-combinations or a transformation of them $(j, k, \cdots, r)$, were considered as the regression variables matrix, (i.e. $\boldsymbol{X}=\left[\mathbf{1}, \boldsymbol{x}_{j}, \boldsymbol{x}_{k}, \cdots, \boldsymbol{x}_{r}\right]$ ). $\boldsymbol{\beta}=\left[\beta_{0}, \beta_{j}, \beta_{k}, \cdots, \beta_{r}\right]$ is the vector of the regression coefficients. The matrix notation was reported in Eq. 5 .

$\boldsymbol{y}=\boldsymbol{X} \cdot \boldsymbol{\beta}+\boldsymbol{\epsilon}$

The estimation of the unknown regression coefficients $\hat{\boldsymbol{\beta}}$ was carried out through the least squares minimization. Indeed, Eq. 6 brings to Eq. 7 .

$L=\boldsymbol{\epsilon}^{\prime} \cdot \boldsymbol{\epsilon}=(\boldsymbol{y}-\boldsymbol{X} \boldsymbol{\beta})^{\prime} \cdot(\boldsymbol{y}-\boldsymbol{X} \boldsymbol{\beta})$

$\hat{\boldsymbol{\beta}}=\left(\boldsymbol{X}^{\prime} \boldsymbol{X}\right)^{-1} \boldsymbol{X}^{\prime} \boldsymbol{y}$

The developed models were also validated assessing the predicting capabilities on additional wear tests, executed for this specific purpose.

\section{Results and discussion}

In this section, the analysis of the performed wear tests was presented. The achieved tool life $T L$ data were reported in Table 4. For sake of completeness, 30 total wear tests were carried out. 9 tests were executed at constant speed machining CSM: 4 tests considering the parameters $v_{c}-f$ combinations according to Table 1 and 5 central point tests. 21 tests were carried out in the sinusoidal spindle speed variation $S S S V$ regime. 16 test conditions were originated combining the $S S S V$ factors $\left(v_{c}, f\right.$, $R V A$, freq, see Table 2) while 5 tests were performed considering intermediate parameter values. A graphical representation of the initial experimental scheme is reported in Fig. 10 (left side). As already explained in the previous paper section, at the beginning, the results of the cutting tests performed at $C S M$ and adopting the $S S S V$ were separately analysed. The idea underpinning the conceived experimental campaigns was based on the suspicion that not all the parameters describing the speed modulating law really affect the life of the tool $T L$. If it is the case, the data coming from each plan could be grouped and can be analysed allowing the development of a general modelling. Before doing the analysis, a natural logarithmic transformation was performed on the following factors: $T L$ (expressed in min), $v_{c}, f, R V A$, freq.

\subsection{CSM modelling}

The transformed tool life data $\ln T L$, obtained in the constant speed machining CSM experimental session, were analyzed through the ANOVA [44]. For sake of generality, according to Eq. 8, the Fisher's statistics $F$ - value ${ }_{j}$ and the associated $P$ - value ${ }_{j}$ were computed for each generic factor $j$ considered in the model. $S S_{j}^{I I I}$ is the adjusted (type III) sum of squares for the factor $j$, obtained removing any possible confounding due to the the remaining factors added to the model, Eq. 9. $S S_{(j, k, \ldots, r)}$ is the sequential sum of squares (type $I$ ) of the model considering the $j, k, \ldots, r$ factors while $S S_{(k, \ldots, r)}$ is the sum of squares (type $I$ ) considering a model with a subset of factors $(k, \ldots, r)$, thus excluding the one under investigation [44]. $M S_{j}$ is the resultant mean of squares $\left(M S_{j}=S S_{j}^{I I I} / D F_{j}\right)$ while $D F_{j}$ is the correspondent degrees of freedom. As expected, the main affecting factors were $\ln v_{c}$ and $\ln f$ while their interaction is not statistically relevant. The ANOVA results considering the main factors were reported in Table 5. For sake of completeness, the analyses performed on the residuals were summarize in Fig. 7. In addition, the regression equation (Eq. 10) was even outlined through the least square $L_{C S M}$ minimization, Eq. 6. All the estimated regression coefficients $\left(\hat{\beta}_{j-C S M}, \cdots, \hat{\beta}_{r-C S M}\right)$ and the corresponding 95\% confidence intervals $C I$ were reported in Table 6 . As suggested in [44], the $\boldsymbol{C I}$ were computed estimating the standard error $\boldsymbol{S} \boldsymbol{E}_{\boldsymbol{C S M}}=\sqrt{\operatorname{diag}\left(\operatorname{Cov}\left(\hat{\boldsymbol{\beta}}_{C S M}\right)\right)}$. The last two columns in Table 6 reported the $t$-student $t$ - test statistic values and the corresponding $P$ - values that measure how the model parameters are usefulness in the proposed formulation. The coefficient of determination $R_{C S M}^{2}=99.26 \%$ and the adjusted statistic $R_{a d j-C S M}^{2}=$ $96.92 \%$. It is worth noting that the statistical test on curvature (associated to the added center point) showed a 
Table 4 Tool life test results - $C S M$ and $S S S V$ factorial designs

\begin{tabular}{|c|c|c|c|c|c|c|c|c|}
\hline Cutting edge number & Run order & Center point & Mode & $v_{c}(\mathrm{~m} / \mathrm{min})$ & $f(\mathrm{~mm} /$ tooth $)$ & $R V A$ & freq & $T L(s)$ \\
\hline 15 & 1 & 0 & $S S S V$ & 160 & 0.3 & 0.3 & 1.5 & 767.3 \\
\hline 2 & 2 & 0 & $C S M$ & 220 & 0.1 & 0 & 0 & 765.6 \\
\hline 3 & 3 & 0 & $S S S V$ & 160 & 0.3 & 0.1 & 0.5 & 1011.1 \\
\hline 4 & 4 & 0 & $C S M$ & 220 & 0.3 & 0 & 0 & 345.6 \\
\hline 14 & 5 & 0 & $S S S V$ & 220 & 0.1 & 0.3 & 1.5 & 574.6 \\
\hline 5 & 6 & 1 & $C S M$ & 190 & 0.2 & 0 & 0 & 798.2 \\
\hline 8 & 7 & 0 & $S S S V$ & 220 & 0.3 & 0.3 & 0.5 & 310.0 \\
\hline 1 & 8 & 0 & $C S M$ & 160 & 0.1 & 0 & 0 & 2736.5 \\
\hline 13 & 9 & 0 & $S S S V$ & 160 & 0.1 & 0.3 & 1.5 & 2471.9 \\
\hline 23 & 10 & 0 & $C S M$ & 160 & 0.3 & 0 & 0 & 1062.1 \\
\hline 24 & 11 & 0 & $S S S V$ & 220 & 0.3 & 0.1 & 0.5 & 337.8 \\
\hline 17 & 12 & 1 & $S S S V$ & 190 & 0.2 & 0.1 & 1 & 641.4 \\
\hline 11 & 13 & 0 & $S S S V$ & 160 & 0.3 & 0.1 & 1.5 & 896.8 \\
\hline 6 & 14 & 0 & $S S S V$ & 220 & 0.1 & 0.3 & 0.5 & 661.8 \\
\hline 12 & 15 & 0 & $S S S V$ & 220 & 0.3 & 0.1 & 1.5 & 348.1 \\
\hline 16 & 16 & 0 & $S S S V$ & 220 & 0.3 & 0.3 & 1.5 & 305.7 \\
\hline 10 & 17 & 0 & $S S S V$ & 220 & 0.1 & 0.1 & 1.5 & 816.1 \\
\hline 25 & 18 & 0 & $S S S V$ & 160 & 0.1 & 0.3 & 0.5 & 1830.9 \\
\hline 21 & 19 & 0 & $S S S V$ & 160 & 0.1 & 0.1 & 0.5 & 2331.5 \\
\hline 07 & 20 & 0 & $S S S V$ & 160 & 0.3 & 0.3 & 0.5 & 764.9 \\
\hline 22 & 21 & 0 & $S S S V$ & 220 & 0.1 & 0.1 & 0.5 & 856.0 \\
\hline 09 & 22 & 0 & $S S S V$ & 220 & 0.1 & 0.1 & 1.5 & 2891.3 \\
\hline 20 & 23 & 1 & $C S M$ & 190 & 0.2 & 0 & 0 & 856.9 \\
\hline 18 & 24 & 1 & $S S S V$ & 190 & 0.2 & 0.2 & 1 & 727.4 \\
\hline 26 & 25 & 1 & $C S M$ & 190 & 0.2 & 0 & 0 & 853.1 \\
\hline 19 & 26 & 1 & $S S S V$ & 190 & 0.2 & 0.2 & 1 & 791.0 \\
\hline 30 & 27 & 1 & $C S M$ & 190 & 0.2 & 0 & 0 & 804.4 \\
\hline 29 & 28 & 1 & $S S S V$ & 190 & 0.2 & 0.2 & 1 & 739.8 \\
\hline 28 & 29 & 1 & $C S M$ & 190 & 0.2 & 0 & 0 & 867.4 \\
\hline 27 & 30 & 1 & $S S S V$ & 190 & 0.2 & 0.2 & 1 & 723.4 \\
\hline
\end{tabular}

quite high $P-$ value, this means that the linearity in the factors effect cannot be confuted.

$$
\begin{aligned}
& F-\text { value }_{j}=\frac{S S_{j}^{I I I} / D F_{j}}{S S_{\text {error }} / D F_{\text {error }}} \\
& S S_{j}^{I I I}=S S_{(j \mid k, \ldots, r)}=S S_{(j, k, \ldots, r)}-S S_{(k, \ldots, r)} \\
& y_{C S M} \equiv \begin{array}{l}
\ln T L_{C S M}=\hat{\beta}_{0-C S M}+\hat{\beta}_{l n v_{c}-C S M} \cdot \ln v_{c} \\
+\hat{\beta}_{l n f-C S M} \cdot \ln f
\end{array}
\end{aligned}
$$

\subsection{SSSV modelling}

The described methodology (Section 3.1) was adopted even for analysing the transformed $\ln T L$ data obtained from the experimental campaign performed in the sinusoidal spindle speed $S S S V$ regime. The ANOVA results, considering the main factors $\left(\ln v_{c}, \ln f, \ln R V A\right.$ and $\ln$ freq $)$ and the 2 - ways interactions, were reported in Table 7 .

As can be observed, the relevant factors to be considered in the $S S S V$ formulation are respectively $\ln v_{c}, \ln f$, $\ln R V A$ while $\ln$ freq seems not affecting the life of the tool. The effect of $S S S V$ cutting can be also observed in Fig. 8 where the $V B B_{i k}$ associated to the tests carried out in both the center points (Fig. 10, left side) were reported. Five repetitions for each cutting condition (CSM or SSSV) were performed. Although the results were affected by the process variability, it is quite evident that the tools adopted for the $S S S V$ cutting showed a reduced $T L$. The ANOVA residuals analysis was reported in Fig. 9. Even in this case, the regression equation was obtained (Eq. 11) as well as the $R_{S S S V}^{2}=97.93 \%$ and the adjusted statistic $R_{a d j-S S S V}^{2}=97.69 \%$. For sake of simplicity, it was 
Table 5 CSM: ANOVA results

\begin{tabular}{|c|c|c|c|c|c|}
\hline Source & $D F$ & $S S_{j}^{I I I}$ & $M S_{j}$ & $F-$ value & $P$-value \\
\hline Model & 2 & 2.21858 & 1.10929 & 403.05 & 0.000 \\
\hline Linear & 2 & 2.21858 & 1.10929 & 403.05 & 0.000 \\
\hline $\ln v_{c}$ & 1 & 1.43110 & 1.43110 & 519.97 & 0.000 \\
\hline $\ln f$ & 1 & 0.76357 & 0.76357 & 277.43 & 0.000 \\
\hline Error & 6 & 0.01651 & 0.00275 & & \\
\hline Curvature & 1 & 0.00481 & 0.00481 & 2.06 & 0.211 \\
\hline Lack of Fit & 1 & 0.00570 & 0.00570 & 3.80 & 0.123 \\
\hline Pure Error & 4 & 0.00600 & 0.00150 & & \\
\hline Total & 8 & 2.23509 & & & \\
\hline
\end{tabular}



Histogram

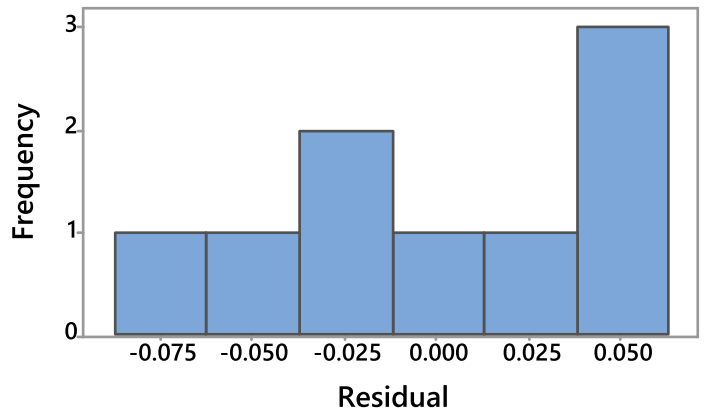

VersusFits

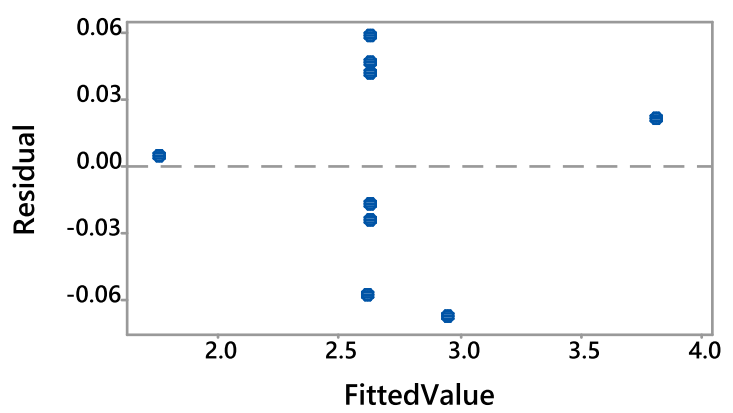

VersusOrder

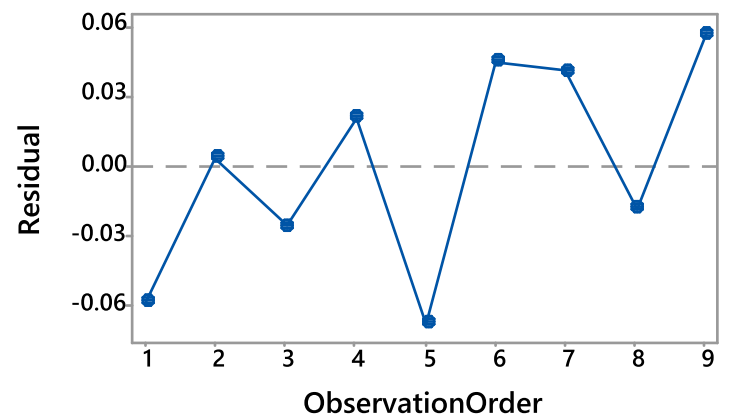

Fig. 7 CSM: residuals analysis

Table 6 CSM: regression results

\begin{tabular}{llllrr}
\hline Model term CSM & $\hat{\beta}_{C S M}$ & $S E_{C S M}$ & \%95 CI & $t-$ value & $P-$ value \\
\hline Constant & $\hat{\beta}_{0-C S M}=21.035$ & 0.867 & $(18.914 ; 23.155)$ & 24.27 & 0.000 \\
$\ln v_{c}$ & $\hat{\beta}_{l n v_{c}-C S M}=-3.750$ & 0.164 & $(-4.153 ;-3.348)$ & -22.8 & 0.000 \\
$\ln f$ & $\hat{\beta}_{l n f-C S M}=-0.7807$ & 0.0469 & $(-0.8954 ;-0.6660)$ & -16.66 & 0.000 \\
\hline
\end{tabular}


Table $7 S S S V$ : ANOVA results

\begin{tabular}{|c|c|c|c|c|c|}
\hline Source & $D F$ & $S S_{j}^{I I I}$ & $M S_{j}$ & $F-$ value & $P-$ value \\
\hline Model & 11 & 8.22306 & 0.74755 & 77.97 & 0.000 \\
\hline Linear & 4 & 8.06582 & 2.01646 & 210.31 & 0.000 \\
\hline $\ln v_{c}$ & 1 & 4.63283 & 4.63283 & 483.19 & 0.000 \\
\hline $\ln f$ & 1 & 3.25812 & 3.25812 & 339.81 & 0.000 \\
\hline $\ln R V A$ & 1 & 0.17168 & 0.17168 & 17.91 & 0.002 \\
\hline ln freq & 1 & 0.00319 & 0.00319 & 0.33 & 0.578 \\
\hline 2 way inter. & 6 & 0.08812 & 0.01469 & 1.15 & 0.271 \\
\hline $\ln v_{c} \cdot \ln f$ & 1 & 0.04813 & 0.04813 & 5.02 & 0.052 \\
\hline $\ln v_{c} \cdot \ln R V A$ & 1 & 0.00001 & 0.00001 & 0.00 & 0.982 \\
\hline $\ln v_{c} \cdot \ln$ freq & 1 & 0.02038 & 0.02038 & 2.13 & 0.179 \\
\hline $\ln f \cdot \ln R V A$ & 1 & 0.00792 & 0.00792 & 0.83 & 0.387 \\
\hline $\ln f \cdot \ln f r e q$ & 1 & 0.01137 & 0.01137 & 1.19 & 0.304 \\
\hline $\ln R V A \cdot \ln$ freq & 1 & 0.00031 & 0.00031 & 0.03 & 0.861 \\
\hline Curvature & 1 & 0.00873 & 0.00873 & 0.91 & 0.365 \\
\hline Error & 9 & 0.08629 & 0.00959 & & \\
\hline Lack of Fit & 5 & 0.06329 & 0.01266 & 2.20 & 0.232 \\
\hline Pure Error & 4 & 0.02300 & 0.00575 & & \\
\hline Total & 20 & 8.30936 & & & \\
\hline
\end{tabular}

decided to consider in the model formulation the amplitude modulation $R V A$ instead of its logarithmic transformation. Even in this case the linearity in the factors effect cannot be confuted (Table 7). Similarly to CSM modelling, the relevance of the model parameter was reported in Table 8 .

$$
\begin{aligned}
y_{S S S V} \equiv & \ln T L_{S S S V} \\
= & \hat{\beta}_{0-S S S V}+\hat{\beta}_{\ln v_{c}-S S S V} \cdot \ln v_{c} \\
& +\hat{\beta}_{\ln f-S S S V} \cdot \ln f+\hat{\beta}_{R V A-S S S V} \cdot R V A
\end{aligned}
$$

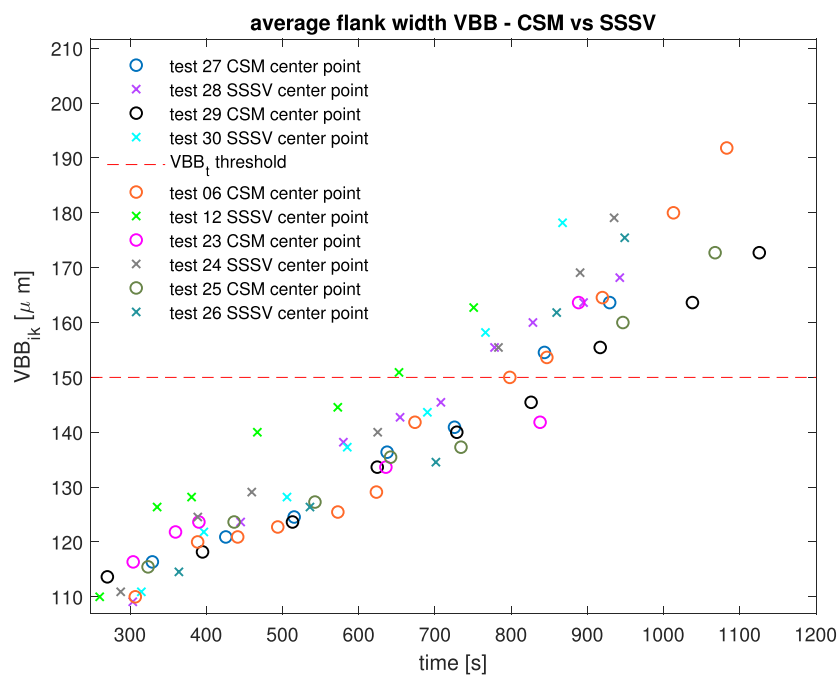

Fig. $8 V B B_{i k}$ evolution: effect of $S S S V$ on $T L$ in the intermediate cutting conditions

\subsection{General model development}

Since the frequency of the speed modulation freq resulted not to be a significant factor, therefore the unreplicated design in four factors conceived for performing the $S S S V$ campaign can be considered a two times replicated plan with three factors: $\ln v_{c}, \ln f$ and $R V A$ (Fig. 10). According to the $C S M$ and SSSV models, the velocity and feed were found to be significant factors in both the cases, while for the $S S S V$ case even $R V A$ resulted to be significant. Since the experimentation performed at $C S M$ can be considered a specific realization of the $S S S V$ formulation (setting $R V A=0$ ), it is interesting to develop a general model considering the whole tool life data-set. For sake of clarity, the resultant graphical representation was reported in Fig. 10. Moreover, the test conditions used for the model formulations validation (see Section 3.4) were put into evidence in Fig. 10, right side.

Before doing that, the test of equality of means was performed on the coefficients present in by both $C S M$ (Section 3.1) and SSSV (Section 3.2) formulations: $H_{0-\text { constant }}: \hat{\beta}_{0-C S M}$ $=\hat{\beta}_{0-S S S V}, H_{0-\ln v_{c}}: \hat{\beta}_{\ln v_{c}-C S M}=\hat{\beta}_{\ln v_{c}-S S S V}, H_{0-\ln f}:$ $\hat{\beta}_{\ln f-C S M}=\hat{\beta}_{\ln f-S S S V}$. All the tests confirmed that the two proposed formulations shared the fitted parameters (the generic null hypotheses $H_{0 k}$ cannot be refused) and this confirmed the adequacy of a general model for interpreting all the experimental data. For sake of completeness, the ANOVA results and the residual analysis were respectively reported in Table 9 and Fig. 11. 


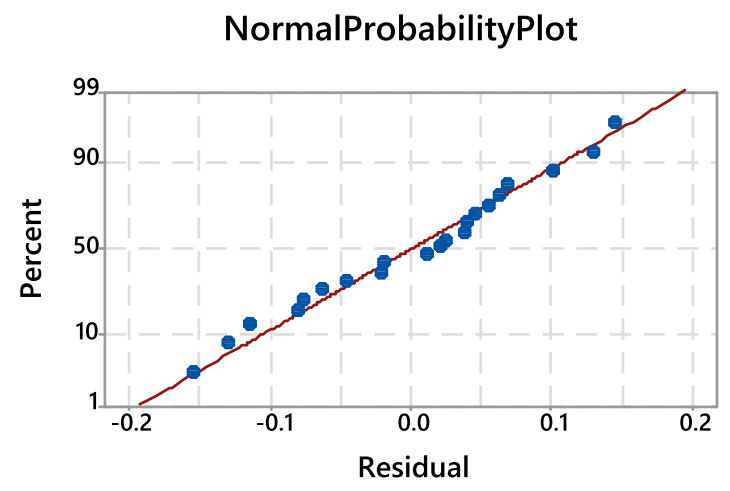

Histogram

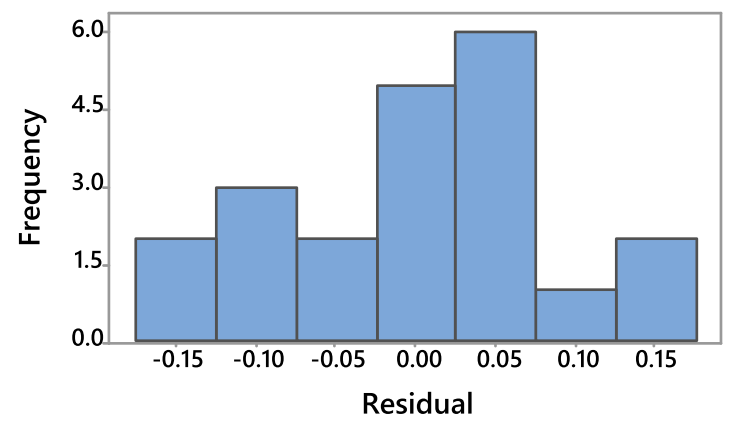

Fig. $9 S S S V$ formulation: residuals analysis

The general model equation and the corresponding identified terms were reported respectively in Eq. 13 and Table 10

$$
\begin{aligned}
y_{g e n} \equiv & \ln T L_{g e n} \\
= & \hat{\beta}_{0-g e n}+\hat{\beta}_{\ln v_{c}-g e n} \cdot \ln v_{c}+\hat{\beta}_{\ln f-g e n} \cdot \ln f \\
& +\hat{\beta}_{R V A-g e n} \cdot R V A
\end{aligned}
$$

\subsection{Model validation and discussion}

In order to validate the model, additional experimental tests were carried out. More specifically, new cutting conditions (both in CSM and SSSV) were tested (Fig. 10). The adopted parameters and the new obtained tool life $T L$ data were reported in Table 11.

\section{VersusFits}

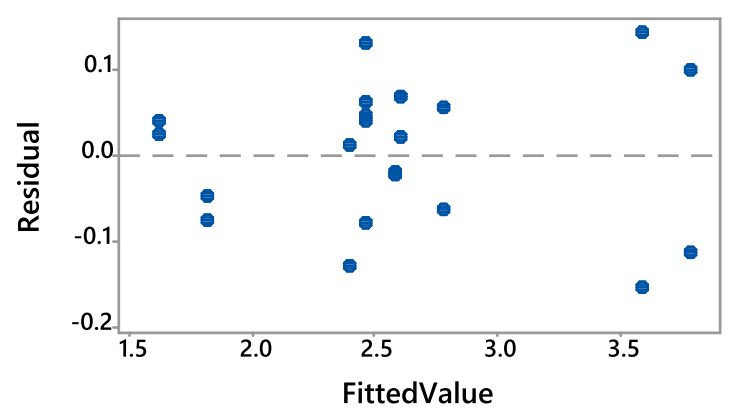

VersusOrder

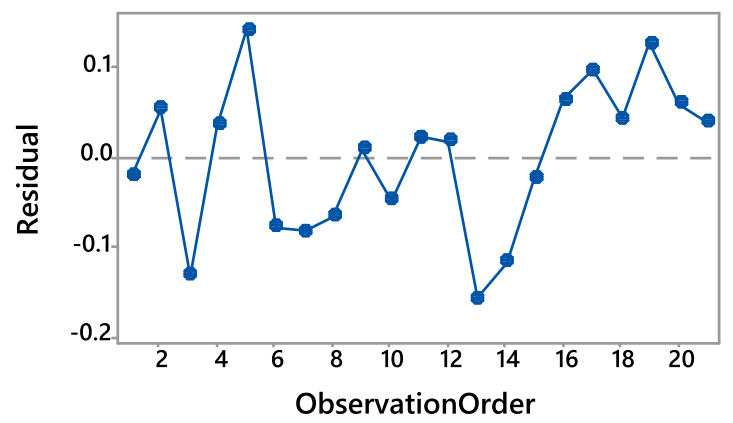

In Table 12, the percentage errors $T L_{s-\text { error\% }}$ (Eq. 14) obtained adopting the $s$ th formulation for the tool life estimation $\hat{T L_{S}}$ were reported. For sake of clarity, as an example, $T L_{g e n-e r r o r \%}$ is the percentage estimation error that results if the tool life is estimated through the general model formulation $\hat{T L_{g e n}}$ (Section 3.3). Other percentage errors can be analogously computed. It can be observed that the developed general model shows limited errors $T L_{\text {gen-error\% }}$ (less than $6 \%$ ) and a lower standard error $S E_{k-\text { gen }}$ for all the shared $\hat{\beta}_{k}$ with respect to the other formulations maybe because it was developed exploiting the full data set. $S S S V$ formulation shows similar performances in terms of estimating errors (less than 5\%) while CSM modelling exhibits a worse performance (although the error is limited to $10 \%$ ) if compared to the other modelling approaches. The estimation errors would increased (ranging from -9.4 to $-16 \%$, see the values reported among brackets in Table 12 in the column $T L_{C S M-\text { error\% }}$ ) if the

Table $8 S S S V$ : regression results

\begin{tabular}{llllrr}
\hline Model Term SSSV & $\hat{\beta}_{S S S V}$ & SE SSSV & \%95 CI & t-value & $P-$ value \\
\hline Constant & $\hat{\beta}_{0-S S S V}=19.075$ & 0.852 & $(17.278 ; 20.873)$ & 22.39 & 0.000 \\
$\ln v_{c}$ & $\hat{\beta}_{\ln v_{c}-S S S V}=-3.376$ & 0.162 & $(-3.717 ;-3.036)$ & -20.9 & 0.000 \\
$\ln f$ & $\hat{\beta}_{\ln f-S S S V}=-0.8186$ & 0.0465 & $(-0.8882 ;-0.7205)$ & -17.61 & 0.000 \\
$R V A$ & $\hat{\beta}_{R V A-S S S V}=-1.036$ & 0.257 & $(-1.136 ;-0.493)$ & -4.02 & 0.001 \\
\hline
\end{tabular}




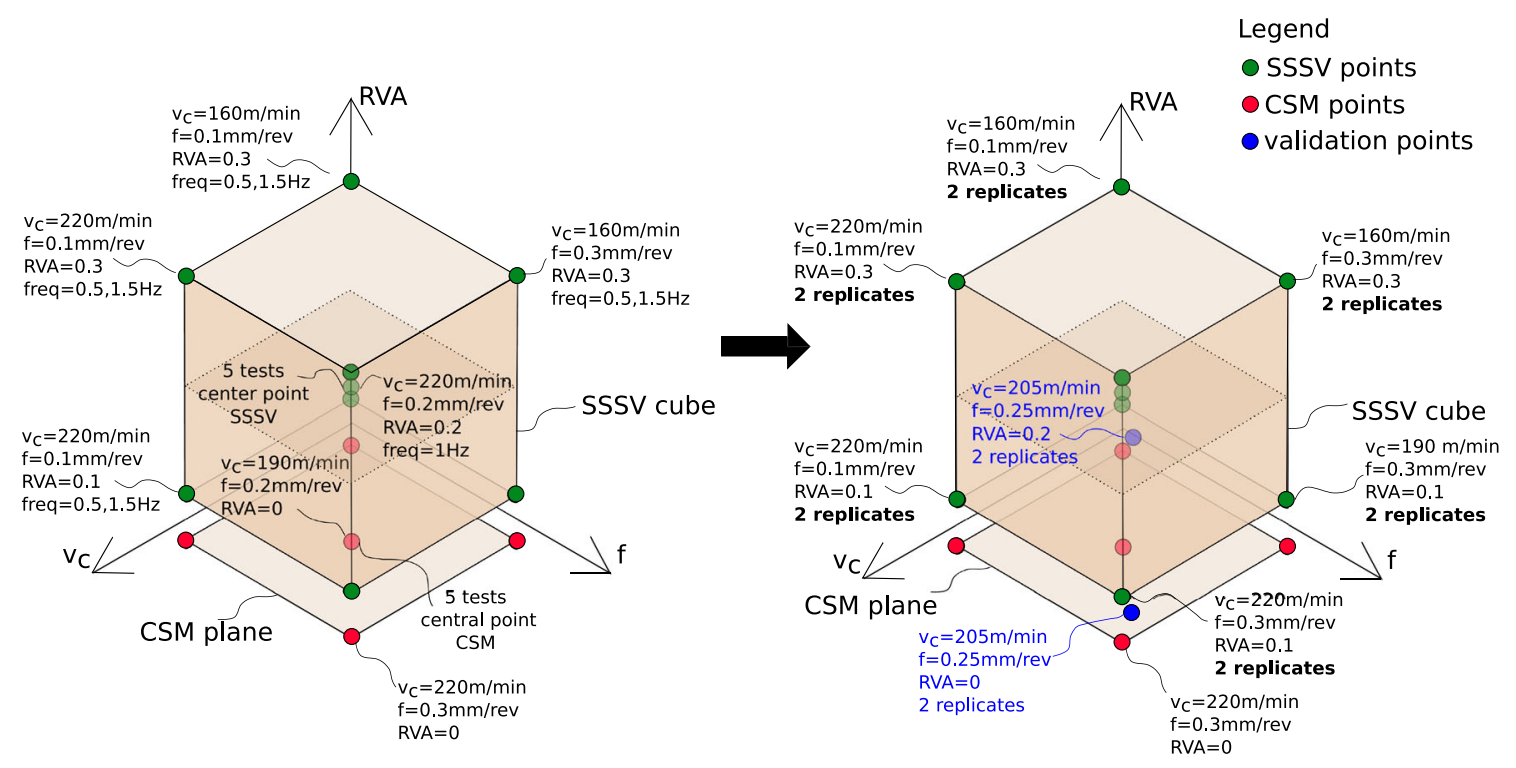

Fig. 10 General model scheme: initial experimental scheme (left) - resulted test representation and validation test conditions (right)

formulation developed for $C S M$ was used for predicting the tool duration performed with the sinusoidal spindle speed variation $S S S V$. As expected, the $C S M$ model overestimates the tool life $T L$ since it does not consider the detrimental effect of the SSSV. On the contrary, the $S S S V$ formulation would behave well (error less than $5 \%$ ) if it was used for estimating the $T L$ of cutting tests performed at $C S M$. Indeed, although the $S S S V$ formulation was developed just considering turning tests performed with $R V A \neq 0$ the model can be used for extrapolation $(C S M)$. For sake of completeness, the values reported among brackets in Table 12 refer to a not proper exploitation of the developed model: for instance, the CSM model for predicting the tool duration in SSSV cutting or vice-versa. Moreover, referring to the specific literature, the maximum observed estimation error adopting the developed general formulation is in accordance with other advanced models suitable only for CSM [32]. This further confirms the adequacy of the proposed modelling approach. Since the limited prediction errors observed for the validation points and the statistical tests on curvature, the linear dependence of the tool life $T L$ on the considered factors can be further confirmed. To the authors' knowledge, no one developed specific formulation for modelling the effect of $S S S V$ on the $T L$. Previous works of the same research group focused mainly on the phenomenological aspects and not on the quantification of the detrimental effects of SSSV when the cutting is stable.

$T L_{S-\text { error } \%}=100 \cdot \frac{T L-\hat{T L_{S}}}{\hat{T L_{S}}}$

Although the limitations of empirical approaches were underlined by Wong et al. [31], the authors believe that the proposed general formulations, in terms of the structure of the model, being developed from Taylor's basic model, is suitable for considering the effects of SSSV on different materials, especially for other steels. The study carried by Johansson et al. [32] supports the previous considerations
Table 9 general: $A N O V A$ results

\begin{tabular}{llllll}
\hline Source & $D F$ & $S S_{j}^{I I I}$ & $M S_{j}$ & $F$-value & $P$-value \\
\hline Model & 3 & 10.3793 & 3.45977 & 410.21 & 0.000 \\
Linear & 3 & 10.3793 & 3.45977 & 410.21 & 0.000 \\
$\ln v_{c}$ & 1 & 6.0553 & 6.05527 & 717.95 & 0.000 \\
$\ln f$ & 1 & 4.0659 & 4.06592 & 482.08 & 0.000 \\
$\ln R$ VA & 1 & 0.2913 & 0.29135 & 34.54 & 0.000 \\
Error & 26 & 0.2913 & 0.00843 & & 0.516 \\
Curvature & 1 & 0.0037 & 0.00374 & 0.43 & 0.221 \\
Lack of Fit & 9 & 0.0995 & 0.01105 & 1.52 & \\
Pure Error & 16 & 0.1161 & 0.00725 & & \\
Total & 29 & 10.5986 & & & \\
\hline
\end{tabular}


NormalProbabilityPlot

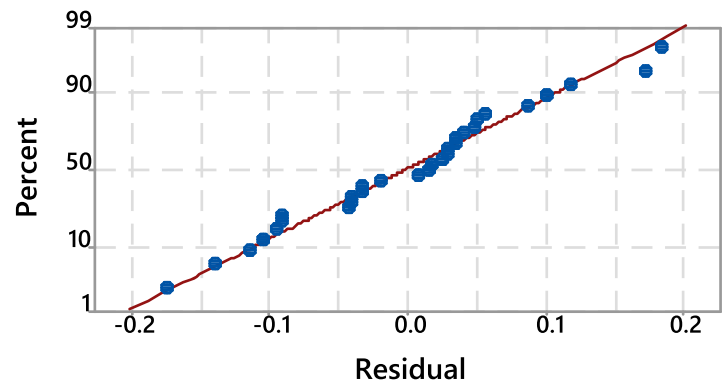

Histogram

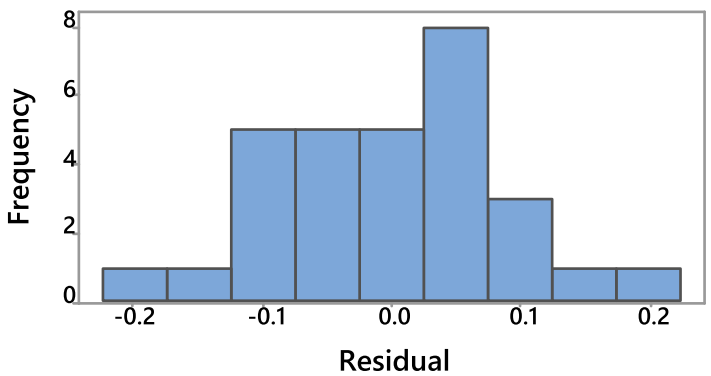

VersusFits

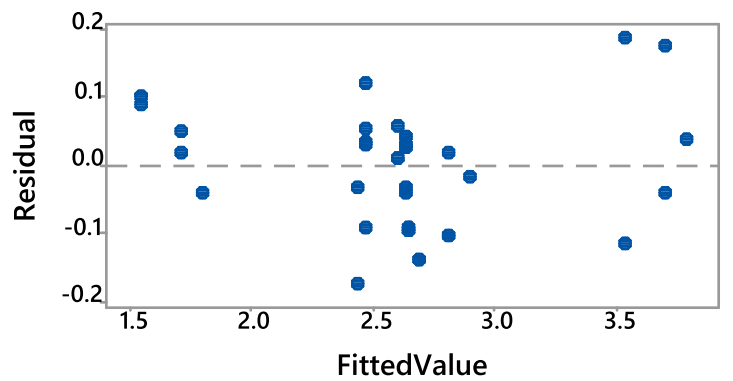

VersusOrder

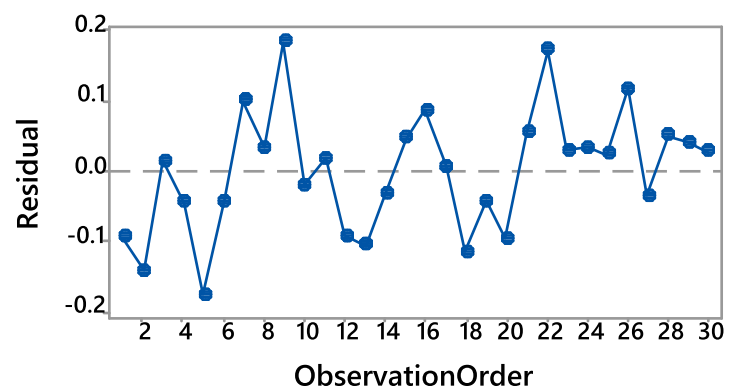

Fig. 11 General residuals analysis

Table 10 General model: regression results

\begin{tabular}{|c|c|c|c|c|c|}
\hline Model Term gen & $\hat{\beta}_{g e n}$ & $S E_{g e n}$ & $\% 95 C I$ & $t$-value & $P$-value \\
\hline Constant & $\hat{\beta}_{0-\text { gen }}=19.438$ & 0.679 & $(18.042 ; 20.834)$ & 28.63 & 0.000 \\
\hline $\ln v_{c}$ & $\hat{\beta}_{\ln v_{c}-g e n}=-3.452$ & 0.129 & $(-3.717 ;-3.188)$ & -26.79 & 0.000 \\
\hline $\ln f$ & $\hat{\beta}_{\ln f-\text { gen }}=-0.8121$ & 0.0370 & $(-0.8882 ;-0.7361)$ & -21.96 & 0.000 \\
\hline$R V A$ & $\hat{\beta}_{R V A-\text { gen }}=-0.842$ & 0.143 & $(-1.136 ;-0.547)$ & -5.88 & 0.000 \\
\hline
\end{tabular}

Table 11 Tool life: tested conditions for the model validation

\begin{tabular}{|c|c|c|c|c|c|c|c|}
\hline Cutter & Test & Mode & $v_{c}[\mathrm{~m} / \mathrm{min}]$ & $f_{z}[\mathrm{~mm} /$ tooth $]$ & $R V A$ & freq & $T L[s]$ \\
\hline 33 & 31 & $S S S V$ & 205 & 0.25 & 0.2 & 1 & 435.1 \\
\hline 34 & 32 & $C S M$ & 205 & 0.25 & 0 & 0 & 559.2 \\
\hline 31 & 33 & $C S M$ & 205 & 0.25 & 0 & 0 & 566.7 \\
\hline 32 & 34 & $S S S V$ & 205 & 0.25 & 0.2 & 1 & 469.1 \\
\hline
\end{tabular}

Table 12 predicting modelling errors

\begin{tabular}{lllllllll}
\hline Cutter & Test & Mode & $\hat{T L_{C S M}[s]}$ & $T L_{C S M-\text { error\% }}$ & $\hat{T L_{S S S V}[s]}$ & $T L_{S S S V-\text { error\% }}$ & $\hat{T L}_{\text {gen }}[s]$ & $T L_{\text {gen-error\% }}$ \\
\hline 33 & 31 & $S S S V$ & $(518.2)$ & $(-16)$ & 457.8 & -4.96 & 452.5 & -3.84 \\
34 & 32 & $C S M$ & 518.2 & 7.92 & $(563.23)$ & $(-0.71)$ & 535.5 & 4.44 \\
31 & 33 & $C S M$ & 518.2 & 9.37 & $(563.23)$ & $(0.62)$ & 535.5 & 5.84 \\
32 & 34 & $S S S V$ & $(518.2)$ & $(-9.4)$ & 457.8 & 2.46 & 452.5 & 3.67 \\
\hline
\end{tabular}


since they found that Taylor's model works fine within a quite broad range of materials (steels, cast irons and stainless steels). Previous research works that focused on the phenomenological aspects that make the $T L$ of $S S S V$ cutting shorter than CSM can help understanding the potentialities of the developed formulation. Albertelli et al. [42] found that during $S S S V$ turning a crack on the insert fosters the coating delamination and therefore a faster wear of the tool. This was observed considering the same insert-working material of the present study. Chiappini et al. [25] studied the mechanics of chip formation in $S S S V$ turning of Ti6Al4V (heat resistant alloy HRA) and adopting a different insert geometry. It was found that, in view of the fact that the modulation of the cutting speed origins a fluctuation of the maximum cutting temperature and a peak of pressure on the inserts, thermal gradients and a subsequent thermal fatigue can affect the tool. According to other research works (i.e. Evans and Hutchinson [45]) that found that thermal gradients and thermal fatigue are the main relevant causes of coating delamination, it can be concluded that this was the cause of the observed detrimental effect of $S S S V$ on the wear of the tool. Since the thermal fatigue is mainly associated to the speed modulation [25], it can be stated that an analogous $T L$ reduction can be expected regardless the processed material. These considerations bring to conclude that the proposed formulation could be used for a wide range of materials especially if coated inserts are used. Moreover, since spindle speed variation is typically used for suppressing unstable cutting, its application is particularly suitable for roughing operations in which high depths of cut are involved.

\section{Conclusions}

A generalized model for the prediction of the tool duration in steel turning when the sinusoidal spindle speed $S S S V$ is used was developed and presented. The proposed formulation is even suitable for modelling CSM constant speed machining. The model was outlined exploiting tool wear tests performed in different cutting conditions. Since the conceived tool life model takes into account the detrimental effects of spindle speed on tool life $T L$, it could be used to widely analyse the economic feasibility of the technique in different cutting scenarios and applications. The following results can therefore be summarised:

- The statistical analysis performed on the experimental data confirmed that the continuous modulation of the spindle speed, while keeping the feed velocity constant, negatively affects the achievable useful life of the tool.

- From the experimental session carried out with the sinusoidal spindle speed modulation it was found that the modulating frequency freq does not affect the tool duration.

- A specific tool life model formulation for $S S S V$ was developed exploiting the experimental test results. The normalized amplitude of the spindle modulation $R V A$, together with the other affecting parameters (cutting speed $v_{c}$ and feed $f$ ), was included in the model.

- According to the previous reported findings, it was possible to develop a generalized tool life model formulation that can be indifferently used both in regular cutting regime $C S M$ and when the $S S S V$ is adopted.

- The generalized formulation was validated performing additional tool life tests. It was found that it capable of predicting the useful tool life within a maximum estimating error of $6 \%$

Future research efforts will be surely focused on a broader validation and on a generalization of the developed model. Although there are some hints that bring to consider the proposed general formulation robust to changes in workpiece material and tool geometry, a proper validation would be extremely valuable. Moreover, even the model generalization considering the effect of the depth of cut could be developed.

Acknowledgements The authors would tank Eng. Sing that supervised the experimental test execution and Professor Semeraro for his valuable tips in the experimental campaign definition. The present research was developed in the framework of a project ("CLUSTER: High Performance Manufacturing” - CT N0100163216758) founded by $M I U R$ (The Italian Ministry of Education and Research).

Author contribution Paolo Albertelli conceived the research, performed the tests, made the analysis, wrote the paper. Valerio Mussi: performed the tests; Michele Monno carried out the proof-reading.

Funding Open access funding provided by Politecnico di Milano within the CRUI-CARE Agreement. Partial financial support was received by MIUR (Italy)

Availability of data and materials Data are reported in the paper

\section{Declarations}

Ethics approval This research follows ethical standards

Consent for publication The authors consent for publication.

Consent for participate The authors agree.

Conflict of interest The authors declare no competing interests.

Open Access This article is licensed under a Creative Commons Attribution 4.0 International License, which permits use, sharing, adaptation, distribution and reproduction in any medium or format, as long as you give appropriate credit to the original author(s) and the source, provide a link to the Creative Commons licence, and indicate if changes were made. The images or other third party material in this article are included in the article's Creative Commons licence, unless 
indicated otherwise in a credit line to the material. If material is not included in the article's Creative Commons licence and your intended use is not permitted by statutory regulation or exceeds the permitted use, you will need to obtain permission directly from the copyright holder. To view a copy of this licence, visit http://creativecommons. org/licenses/by/4.0/.

\section{References}

1. Altintas Y, Weck M (2004) Chatter stability of metal cutting and grinding. CIRP Annals - Manufacturing Technology 53(2):619 642. https://doi.org/10.1016/S0007-8506(07)60032-8

2. Siddhpura M, Paurobally R (2012) A review of chatter vibration research in turning. International Journal of Machine Tools and Manufacture 61:27-47. https://doi.org/10.1016/J. IJMACHTOOLS.2012.05.007

3. Munoa J, Beudaert X, Dombovari Z, Altintas Y, Budak E, Brecher C, Stepan G (2016) Chatter suppression techniques in metal cutting. CIRP Annals - Manufacturing Technology 65(2):785808. https://doi.org/10.1016/j.cirp.2016.06.004

4. Radulescu R, Kapoor S, DeVor R (1997) An Investigation of variable spindle speed face milling for tool-work structures with complex dynamics, part 1: simulation results. Transactions of ASME Journal of Manufacturing Science and Engineering 119(3):266-272

5. Insperger T, Schmitz T, Burn T, Stépán G (2003) Comparison of analytical and numerical simulations for variable spindle speed turning. Proceedings of IMECE'03 International Mechanical Engineering Congress, 1-7 Washington, D.C., United States

6. Insperger T (2004) Stability analysis of turning with periodic spindle speed modulation via semidiscretization. Journal of Vibration and Control 10(12):1835-1855. https://doi.org/10.1177/ 1077546304044891

7. Kapoor SG, Devor RE (2000) Analytical stability analysis of variable spindle speed machining. J Manuf Sci Eng 122(3):391397

8. Albertelli P, Musletti S, Leonesio M, Bianchi G, Monno M (2012) Spindle speed variation in turning: technological effectiveness and applicability to real industrial cases. The International Journal of Advanced Manufacturing Technology 62(1):59-67

9. Urbikain G, Olvera D, de Lacalle LN, Elías-Zúñiga A (2016) Spindle speed variation technique in turning operations: modeling and real implementation. Journal of Sound and Vibration 383:384-396. https://doi.org/10.1016/J.JSV.2016.07.033

10. Yamato S, Matsuzaki H, Ito T, Kakinuma Y (2020) Investigation of correlation between process energy balance and phase shift variation of chatter vibration in spindle speed variation. JSME 2020 Conference on Leading Edge Manufacturing/Materials and Processing, LEMP 2020 https://doi.org/10.1115/LEMP2020-8565

11. Zhang $\mathrm{H}$, Ni J (2009) Internal energy based analysis on mechanism of spindle speed variation for regenerative chatter control. Journal of Vibration and Control 16(2):281-301. https://doi.org/10.1177/1077546309103562

12. Otto A, Radons G (2013) Application of spindle speed variation for chatter suppression in turning. CIRP Journal of Manufacturing Science and Technology 6(2):102-109. https://doi.org/10.1016/J.CIRPJ.2013.02.002

13. Wu D, Chen K (2010) Chatter suppression in fast tool servo-assisted turning by spindle speed variation. International Journal of Machine Tools and Manufacture 50(12):1038-1047. https://doi.org/10.1016/J.IJMACHTOOLS.2010.09.001

14. Ding L, Sun Y, Xiong Z (2020) Active chatter suppression in turning by simultaneous adjustment of amplitude and frequency of spindle speed variation. Journal of Manufacturing Science and Engineering, Transactions of the ASME 142(2):1-10. https://doi.org/10.1115/1.4045618

15. Ding L, Sun Y, Xiong Z (2018) Online chatter suppression in turning by adaptive amplitude modulation of spindle speed variation. Journal of Manufacturing Science and Engineering 140(12). https://doi.org/10.1115/1.4041248

16. Meng HF, Kang Y, Chen Z, Zhao YB, Liu GP (2015) Stability analysis and stabilization of a class of cutting systems with chatter suppression. IEEE/ASME Transactions on Mechatronics 20(2):991-996. https://doi.org/10.1109/TMECH.2014.2319825

17. Zatarain M, Bediaga I, Muñoa J, Lizarralde R (2008) Stability of milling processes with continuous spindle speed variation: analysis in the frequency and time domains, and experimental correlation. CIRP Annals 57(1):379-384. https://doi.org/10.1016/J. CIRP.2008.03.067

18. Totis G, Albertelli P, Sortino M, Monno M (2014) Efficient evaluation of process stability in milling with spindle speed variation by using the Chebyshev collocation method. Journal of Sound and Vibration 333(3):646-668. https://doi.org/10.1016/J.JSV.2013.09. 043

19. Yilmaz A, AL-Regib E, Ni J (2002) Machine tool chatter suppression by multi-level random spindle speed variation. Journal of Manufacturing Science and Engineering 124(2):208. https://doi.org/10.1115/1.1378794

20. Nam S, Hayasaka T, Jung H, Shamoto E (2021) Proposal of novel spindle speed variation profile with constant acceleration rate for improvement of chatter stability. Precision Engineering 68:218 234. https://doi.org/10.1016/J.PRECISIONENG.2020.12.008

21. Nam S, Hayasaka T, Jung H, Shamoto E (2020) Proposal of novel chatter stability indices of spindle speed variation based on its chatter growth characteristics. Precision Engineering 62:121-133. https://doi.org/10.1016/J.PRECISIONENG.2019.11.018

22. Albertelli P, Braghieri L, Torta M, Monno M (2019) Development of a generalized chatter detection methodology for variable speed machining. Mechanical Systems and Signal Processing 123:2642. https://doi.org/10.1016/J.YMSSP.2019.01.002

23. Kayhan M, Budak E (2009) An experimental investigation of chatter effects on tool life. Proceedings of the Institution of Mechanical Engineers, Part B: Journal of Engineering Manufacture 223(11):1455-1463. https://doi.org/10.1243/09544054JEM1506

24. Albertelli P, Mussi V, Ravasio C, Monno M (2012) An experimental investigation of the effects of spindle speed variation on tool wear in turning. Procedia \{CIRP\} 4(0):29-34. https://doi.org/10.1016/j.procir.2012.10.006

25. Chiappini E, Tirelli S, Albertelli P, Strano M, Monno M (2014) On the mechanics of chip formation in Ti-6Al-4V turning with spindle speed variation. International Journal of Machine Tools and Manufacture 77:16-26. https://doi.org/10.1016/J. IJMACHTOOLS.2013.10.006

26. Wojciechowski S, Talar R, Zawadzki P, Wieczorowski M (2020) Evaluation of physical indicators and tool wear during grooving of spheroidal cast iron with a novel WCCo/cBN (BNDCC) inserts. Wear 454-455:203301. https://doi.org/10.1016/j.wear. 2020.203301

27. Wojciechowski S, Twardowski P (2012) Tool life and process dynamics in high speed ball end milling of hardened steel. Procedia CIRP 1:289-294. https://doi.org/10.1016/j.procir.2012. 04.052, Fifth CIRP Conference on High Performance Cutting, 2012

28. Maruda RW, Krolczyk GM, Wojciechowski S, Powalka B, Klos S, Szczotkarz N, Matuszak M, Khanna N (2020) Evaluation of turning with different cooling-lubricating techniques in terms of surface integrity and tribologic properties. Tribology International 148:106334. https://doi.org/10.1016/j.triboint.2020.106334 
29. Albertelli P, Monno M (2021) Energy assessment of different cooling technologies in Ti-6Al-4V milling. The International Journal of Advanced Manufacturing Technology 112:3279-3306. https://doi.org/10.1007/s00170-020-06575-1/Published

30. Albertelli P, Mussi V, Strano M, Monno M (2021) Experimental investigation of the effects of cryogenic cooling on tool life in Ti6Al4V milling. The International Journal of Advanced Manufacturing Technology https://doi.org/10.1007/s00170-02107161-9

31. Wong T, Kim W, Kwon P (2004) Experimental support for a model-based prediction of tool wear. Wear 257(7-8):790-798. https://doi.org/10.1016/J.WEAR.2004.03.010

32. Johansson D, Hägglund S, Bushlya V, Ståhl JE (2017) Assessment of commonly used tool life models in metal cutting. Procedia Manufacturing 11(June):602-609. https://doi.org/10.1016/ j.promfg.2017.07.154

33. Galante G, Lombardo A, Passannanti A (1998) Tool-life modelling as a stochastic process. International Journal of Machine Tools and Manufacture 38(10-11):1361-1369. https://doi.org/10. 1016/S0890-6955(98)00019-4

34. Jemielniak K, Szafarczyk M, Zawistowski J (1985) Difficulties in tool life predicting when turning with variable cutting parameters. CIRP Annals - Manufacturing Technology 34(1):113116. https://doi.org/10.1016/S0007-8506(07)61736-3

35. Lin W (2008) The tool life analysis of ceramic turning tools under the cumulative action of different cutting speeds. Advanced Design and Manufacture to Gain a Competitive Edge, 441-450. Springer

36. Pálmai Z (2014) A model of non-linear cumulative damage to tools at changing cutting speeds. International Journal of
Advanced Manufacturing Technology 74:973-982. https://doi. org/10.1007/s00170-014-6039-5

37. International Standards (1993). ISO 3685: Tool-life testing with single-point turning tools

38. Tsui KL (1996) A critical look at Taguchi's modelling approach for robust design. Journal of Applied Statistics 23(1):81-96. https://doi.org/10.1080/02664769624378

39. Medan N, Lobontiu M, Nagy SR, Dezsõ G (2017) Taguchi versus full factorial design to determine the equation of impact forces produced by water jets used in sewer cleaning. MATEC Web of Conferences 112(03007):1-6. https://doi.org/10.1051/ MATECCONF/201711203007

40. Montgomery D (2001) Design and analysis of experiments. John Wiley adn Sons, 5 th edition

41. Hägglund S (2013) Methods and models for cutting data optimization. Ph.D. thesis, Chalmers University of Technology

42. Albertelli P, Mussi V, Monno M (2014) The analysis of tool life and wear mechanisms in spindle speed variation machining. International Journal of Advanced Manufacturing Technology 72(5-8):1051-1061. https://doi.org/10.1007/s00170-014-5736-4

43. UNI (1978). UNI 7845

44. Montgomery D (2001) Design and analysis of experiments. John Wiley adn Sons, 5th editio edition

45. Evans AG, Hutchinson JW (2007) The mechanics of coating delamination in thermal gradients. Surface and Coatings Technology 201(18):7905-7916. https://doi.org/10.1016/J.SURFCOAT. 2007.03.029

Publisher's note Springer Nature remains neutral with regard to jurisdictional claims in published maps and institutional affiliations. 